\title{
A Concept Model to Scale the Impact of Safety Risk in a Construction Project Using a Semi Quantitative Method
}

\author{
Dewa Ketut Sudarsana \\ Department of Civil Engineering, Faculty of Engineering, University of Udayana, Bali, Indonesia
}

Received December 7, 2020; Revised January 19, 2021; Accepted February 24, 2021

\section{Cite This Paper in the following Citation Styles}

(a): [1] Dewa Ketut Sudarsana, "A Concept Model to Scale the Impact of Safety Risk in a Construction Project Using a Semi Quantitative Method," Civil Engineering and Architecture, Vol. 9, No. 1, pp. 263 -269, 2021. DOI: 10.13189/cea.2021.090122.

(b): Dewa Ketut Sudarsana (2021). A Concept Model to Scale the Impact of Safety Risk in a Construction Project Using a Semi Quantitative Method. Civil Engineering and Architecture, 9(1), 263 - 269. DOI: 10.13189/cea.2021.090122.

Copyright $\mathrm{C} 2021$ by authors, all rights reserved. Authors agree that this article remains permanently open access under the terms of the Creative Commons Attribution License 4.0 International License

\begin{abstract}
The success of a construction project is influenced by variables including time, cost, quality, scope, safety and the environment. These variables all have associated risks. These risks can be managed through the stages of risk identification, risk analysis to determine priority, the risk response itself and risk control. Qualitative and quantitative methods are generally used in the risk analysis stage. A probability-impact (P-I) risk matrix is used for qualitative risk analysis. The weakness of a qualitative risk analysis is that it is not able to provide integrated information on the impact of risks on the project variables, whereas semi-quantitative analysis can alternatively be conducted. The current semi-quantitative description and measurement scale is limited to the P-probability and I-impact for variable cost, quality, time and the scope of the project. The integration of the project constraint variables found is usually a triple constraint which integrates the cost, quality and time variables. The accommodation of global issues in the safety aspects of the project then allows for the development of a diamond model that integrates the variables of cost, quality, time and safety. The development of a semi-quantitative risk analysis is limited by integrating the triple constraint variable where the diamond constraint variable has not been found. This is due to the unavailability of a semi-quantitative safety impact scale. This paper specifically formulates the impact of risk on the safety aspects in a semi-quantitative manner. A descriptive methodology was used for this research. The variance in the safety impact scale was identified from a literature review and the expert judgement method was analyzed through brainstorming with experts. The results of the
\end{abstract}

analysis for the formulation of the safety risk impact scale model using the semi-quantitative method were obtained through the use of a hybrid formulation between the Project Management Body of Knowledge (PMBOK) guidelines and the Standard Australian / Standard New Zealand (AS / NZS) 4360 with a scale of 1 to 5 and a description of the impact starting from very low through to low, moderate, high and very high. It has numeric values of $0.05,0.1,0.2$, 0.4 and 0.8 adopted from the PMBOK while the detailed descriptions were adopted from the AS / AZS 4360 guidelines. This obtained safety scale can be used in integrated risk analysis with semi-quantitative methods and a constraint diamond model with the variables of cost, quality, time and safety.

Keywords Analysis, Semi Quantitative, Impact of Safety Risks, Integration, Construction Projects

\section{Introduction}

Infrastructure projects are intended to enhance the community's economy. However, during the construction implementation period, there are risks to the stakeholders and the environment $[1,2]$. These risks are related to time, cost, quality, scope, resources, safety technologies and the environment. The risk analysis that is commonly used today is either a qualitative or quantitative method of analysis. The qualitative method provides a descriptive description of the impact of the risk using an ordinal 
measurement scale and the quantitative method uses a numerical value measurement scale. The description of the results of the risk analysis of the qualitative method is not yet able to show the priority of the risks. For this reason, a semi-quantitative method was developed. The semi-quantitative method is a hybrid of the qualitative and quantitative methods. At present, the semi-quantitative risk analysis used for risk assessment in construction projects is limited to the aspects of cost, quality, time and scope $[3,4]$. Most project managers are familiar with the project management triangle of quality, cost and time. These three criteria involve project management risks. The combination or relationship between the integration of these risk variables indicates that the strategic risk management decisions are easier to make [5]. Incorporating the cost, quality and time aspects that can allow for more comprehensive strategic risk mitigation decisions to be made [6].

The safety performance in project management

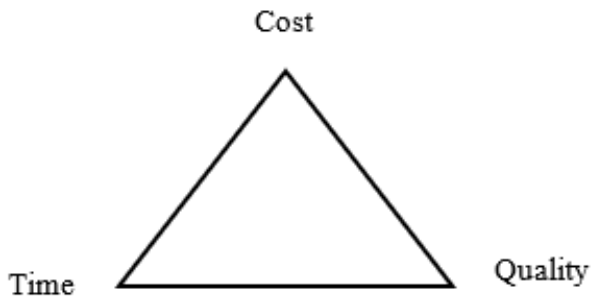

(a) Triple Constraint [7]

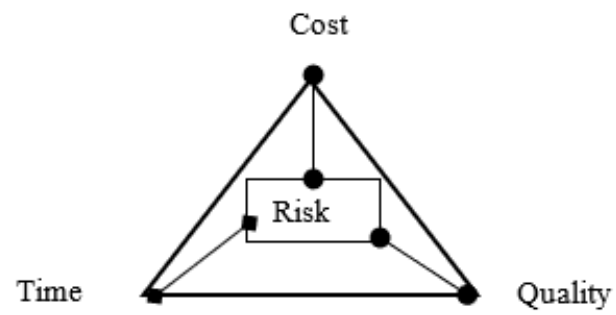

(c) Integration of risk Cost, Time and Quality [13] becomes an important issue and an added baseline within the scope of project performance management. The integration of the 4 types of performance that have been studied includes the variables of cost, quality, time and safety [7]. The parameters for the impact of the risks related to the cost, quality and time aspects using semi-quantitative methods have been studied previously but the impact of the risks of safety has not been realized until now.

\section{Materials and Methods}

The research material is the parameters of the scale used to determine the impact of the safety aspect as the object of the case study of a National road improvement project. The descriptive methodology was used in this research. The research concept framework has been presented in Figure 1.

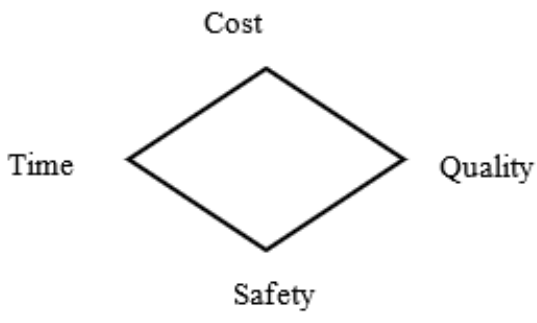

(b) Diamond Constraint [7]

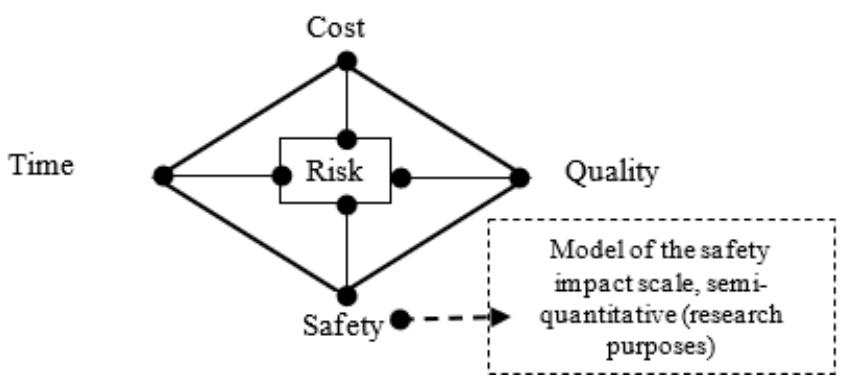

(d) Integrating the risks of Cost, Time, Quality and Safety (concept proposal)

Figure 1. Research Concept Framework 
The research steps and methods used to obtain a safety impact model using a semi-quantitative method were as follows:

1) The conducting of a literature review regarding the impact of ordinal scale hazards and the aspects of different numerical scale categories.

2) Establishing a brainstorming team using a non-probability sampling method [8] to determine the expert team. The designated team of experts consisted of two supervisory advisors, two directors, two entrepreneurs and an academic.

3) Analysis of the dominant category scale from the category scales found by the expert's judgements (3).

4) Brainstorming of the variants of the descriptions for the dominant categories in Step 3) to determine the category descriptions [3].

5) Evaluation of the numerical scale of the predetermined category scale as in Step 4) and then brainstorming the numerical scale using the expert judgement method [3].

\section{Results and Discussion}

\subsection{Risk Impact Categorization Scale}

The results of the literature review of Risk Impact Categories (I) found four groups of categories on a scale of $1-3,1-4,1-5$ and $1-6$.

1) Impact scale (I) with categories $1-3$.

Table 1. Risk impact scale (I) with categories 1 - 3

\begin{tabular}{|c|c|c|c|c|}
\hline \multirow{2}{*}{$\begin{array}{c}\text { Category } \\
\text { scale }\end{array}$} & \multicolumn{4}{|c|}{ Description } \\
\cline { 2 - 5 } & {$[4]$} & {$[9]$} & {$[10]$} & {$[11]$} \\
\hline (a) & (b) & (c) & (d) & (e) \\
\hline 1 & Low & $\begin{array}{c}\text { Slight } \\
\text { accident }\end{array}$ & Light & $\begin{array}{c}\text { Slight } \\
\text { injury }\end{array}$ \\
\hline 2 & Medium & $\begin{array}{c}\text { Severe } \\
\text { accident }\end{array}$ & Moderate & $\begin{array}{c}\text { Severe } \\
\text { injury }\end{array}$ \\
\hline 3 & High & Fatal accident & Weight & Fatal injury \\
\hline
\end{tabular}

The scales used for measuring impact (I) with categories $1-3$ were found in up to 4 reference sources [4, 9-11]. The impact scale with categories $1-3$ has been described in Table 1.

2) Impact scale (I) categories 1 - 4.

The measurement impact scale I with 4 categories of 1 4 was found in a single reference source [12]. The degree of impact described in Scale 4 is catastrophic, Scale 3 is critical, Scale 2 is marginal and Scale 1 is insignificant. This can be seen in Table 2 .

Table 2. Impact scale with categories $1-4$

\begin{tabular}{|c|c|}
\hline Category scale & Description severity \\
\hline (a) & (b) \\
\hline 4 & Catastrophic \\
\hline 3 & Critical \\
\hline 2 & Marginal \\
\hline 1 & Negligible \\
\hline
\end{tabular}

Source: [12]

3) Scale of impact (I) categories 1 - 5.

The scale of the impact of measurement I with 5 categories 1 - 5 was presented in 10 reference sources [3, 12-20]. The varying descriptions of the category scale of 1 - 5 can be seen in Table 3. In the columns of Table $3\left(k^{*}\right)$, there are 5 class descriptions but there are differences in the ordinal scales from $0-4$ [20]. Some authors have developed a category scale from $1-5$ in detail. A detailed description of the five categories under AS/NZS 4360 is shown in Table 4. Several sources complement the description of the impact of the category $1-5$ scale with linear and non-linear cardinal numerical scales $[3,4]$ which can be seen in Table 5 based on the PMBOK guidelines [3]. In Table 5, impact I may already be reported in semi-quantitative parameters since the scale 1 - 5 is a combination of qualitative and quantitative data. The qualitative description is always very short. This makes it more difficult for the respondents to understand.

Table 3. Description of the impact scale (I) with 5 categories of 1 - 5

\begin{tabular}{|c|c|c|c|c|c|}
\hline \multirow{2}{*}{ Category scale } & \multicolumn{5}{|c|}{ Description } \\
\hline & [3] & [12] & [13] & [14] & {$[15]$} \\
\hline (a) & (b) & I & (d) & I & (f) \\
\hline 1 & Very Low & Negligible & Very Low & Insignificant & Single fatality \\
\hline 2 & Low & Minor & Low & Minor & 2-10 Fatalities \\
\hline 3 & Moderate & Serious & Moderate & Moderate & 11-50 Fatalities \\
\hline 4 & High & Fatal & High & Major & 51-100 Fatalities \\
\hline 5 & Very High & Catastrophic & Very High & Severe & $100+$ Fatalities \\
\hline
\end{tabular}


Table 3. Description of the impact scale (I) with 5 categories of 1 - 5 (continued)

\begin{tabular}{|c|c|c|c|c|c|}
\hline \multirow{2}{*}{ Category scale } & \multicolumn{5}{|c|}{ Description } \\
\cline { 2 - 6 } & {$[16]$} & {$[17]$} & {$[3]$} & {$[12]$} & {$[13]$} \\
\hline$(\mathrm{a})$ & $(\mathrm{g})$ & $(\mathrm{h})$ & $(\mathrm{i})$ & $(\mathrm{j})$ & Negligible \\
\hline 1 & Insignificant & Insignificant & Level 1 & Very Low & Marginal \\
\hline 2 & Minor & Minor & Level 2 & Low & Serious \\
\hline 3 & Moderate & Moderate & Level 3 & Moderate & Critical \\
\hline 4 & Major & Major & Level 4 & High & Catastrophic \\
\hline 5 & Catastrophic & Catastrophic & Level 5 & Very High & \\
\hline
\end{tabular}

Table 4. Detailed description of the impact (I) in accordance with AS/ NZS 4360

\begin{tabular}{|c|c|c|}
\hline Category scale & Description & Detailed description \\
\hline 1 & Insignificant & No injuries, low financial loss \\
\hline 2 & Minor & First aid treatment, on site release immediately contained, medium financial loss \\
\hline 3 & Moderate & $\begin{array}{c}\text { First aid treatment required, on site release contained with outside assistance, high financial } \\
\text { loss }\end{array}$ \\
\hline 4 & Major & $\begin{array}{c}\text { Extensive injuries, loss of production capability, off-site release with no detrimental } \\
\text { effects, major financial loss }\end{array}$ \\
\hline 5 & Catastrophic & Death, toxic release off-site with detrimental effect, huge financial loss \\
\hline
\end{tabular}

Source: [3]

Table 6. Description of impact scale I on a scale of $1-6$.

\begin{tabular}{|c|c|c|c|c|c|c|}
\hline \multirow{2}{*}{$\begin{array}{c}\text { Category } \\
\text { scale }\end{array}$} & \multicolumn{6}{|c|}{ Description } \\
\hline & {$[21]$} & {$[22]$} & [23] & [24] & {$[25]$} & [26] \\
\hline (a) & (b) & I & (d) & I & (f) & (g) \\
\hline 1 & Not Significant & None & Negligible & Noticeable & Minor injury & Negligible \\
\hline 2 & Very Low & Very Low & Very Low & Important & $\begin{array}{c}\text { No serious disabling } \\
\text { injury }\end{array}$ & Very low \\
\hline 3 & Low & Low & Low & Very serious & $\begin{array}{c}\text { Extremely serious } \\
\text { injury }\end{array}$ & Low \\
\hline 4 & Medium & Medium & Medium & Serious & Fatality & Middle \\
\hline 5 & High & High & High & Disaster & Multiple fatalities & High \\
\hline 6 & Very High & Very High & Very High & Catastrophe & $\begin{array}{c}\text { Catastrophe, } \\
\text { numerous fatalities }\end{array}$ & Very high \\
\hline
\end{tabular}

4) Impact scale (I) categories 1 - 6.

Impact scale (I) with a class scale of 1 - 6 has been proposed with up to 6 reference sources [21-26]. A description of the scale for categories 1- 6 has been given in Table 6.

In Tables 1, 2, 3 and 4, it can be seen that the references related to risk impact (I) to date have been found. There are 4 references for the category scale of $1-3,1$ reference for the category scale of $1-4,10$ references for the scale of $1-5$ and 6 references for the scale of $1-6$ which graphically can be seen in Figure 2.

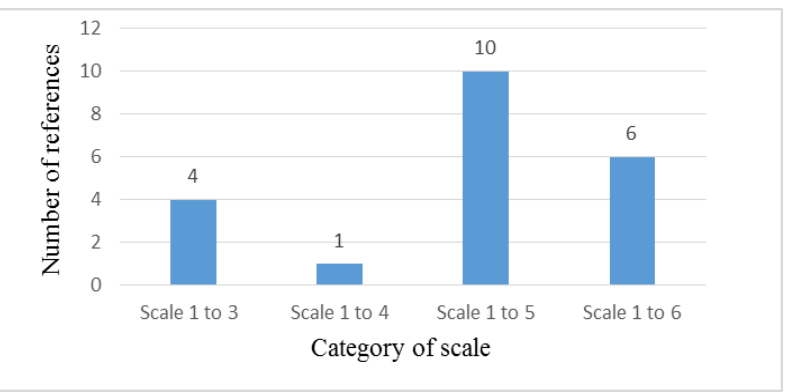

Figure 2. Reference Frequency Plot by Risk Impact Category Scale (I) 


\subsection{Analysis of Impact Safety (I)}

The expert judgment method was performed through brainstorming with the chosen experts. This was used to analyze and determine the category scale, the operational descriptions of the category scale and to determine its numerical size. In Figure 2, it was determined that the category scale 1 to 5 is found to be at most 10 characters. The category scale of $1-6$ is 6 references, a scale of $1-3$ is 4 references and a scale of $1-4$ is only 1 reference. If scale 1 is reached on a scale of 1 to 6 in Table 6 , the ordinal scale in Category 1 explains that almost all of the descriptions indicate that the impact of the risk is insignificant or does not have any impact. If scale 1 is ignored on a scale of $1-6$, the descriptions are equivalent to a scale of $1-5$. The expert brainstorming results state that a scale of $1-5$ was chosen as the impact scale based on the frequency of the most widely used scale of $1-5$ (10 references). The description of the impact scale of 1 5 can be observed in Table 3, which indicates that the description of each class of ordinal scale varies greatly. The results of the brainstorming in the description formulation phase involve the selected 3 references used for the descriptions of the categories $1-5$, namely the PMBOK guidelines [3], the AS / NSZ_4360 [16] guidelines and BSN [17], as seen in Table 7.

The description of the impact of the risk on a scale of 1 to 5 among the 3 selected references as in Table 7 was followed by a more in-depth brainstorm. The description of the brainstorming results was used to formulate the category scale of $1-5$ to combine the PMBOK guidelines'
[3] brief description as shown in Table 7 column (b) and the detailed descriptions of the AS / NZS 4360 guidelines [16] as in Table 7 column (d). The results of this brainstorming can be seen in Table 8 .

In Table 8, the severity scale of the impact categories (I) is given qualitatively using an ordinal scale. The qualitative measure scale in Table 8 indicates that the scale becoming semi-quantitative, quantitative or numerical is required. The brainstorming results in the numerical scale formulation use a numerical scale referred to in the PMBOK guidelines [3] as shown in Table 5. In Table 5, there are 2 kinds of numerical value models, namely linear and non-linear cardinals. The brainstorming results of the experts formulated a numerical scale with a non-linear cardinal scale with the argument that the basis for implementing a construction project is the time schedule. Project timelines generally have a non-linear trend. Based on the time schedule, the project resources can be allocated. The allocation of project resources has an impact on the cost schedule with a non-linear trend as well. The formulation with a non-linear cardinal scale is in line with the scale found by other researchers for the impacts of cost, quality and time risk using a semi-quantitative scale $[3,13]$. The safety risk impact parameter model (I) using the semi-quantitative method can be formulated using a scale of 1 to 5 with a brief description of the impact ranging from very low to very high. The numerical scale is non-linear cardinal with numerical values of $0.05,0.1,0.2,0.4$ and 0.8 . This numerical scale can be seen in Table 9.

Table 7. The formulas of the impact descriptions that were selected for the scale 1 - 5

\begin{tabular}{|c|c|c|c|c|}
\hline \multirow{3}{*}{$\begin{array}{c}\text { Category scale } \\
\text { (a) }\end{array}$} & \multicolumn{4}{|c|}{ Impact and description } \\
\hline & \multirow{2}{*}{$\begin{array}{l}\text { [3] } \\
\text { (b) }\end{array}$} & \multicolumn{2}{|r|}{ [16] } & \multirow{2}{*}{$\begin{array}{l}{[17]} \\
\text { (e) }\end{array}$} \\
\hline & & (c) & (d) & \\
\hline 1 & Very Low & Insignificant & No injuries, low financial loss & Insignificant \\
\hline 2 & Low & Minor & $\begin{array}{l}\text { First aid treatment, on site release immediately contained, } \\
\text { medium financial loss }\end{array}$ & Minor \\
\hline 3 & Moderate & Moderate & $\begin{array}{c}\text { First aid treatment required, on site release contained with } \\
\text { outside assistance, high financial loss }\end{array}$ & Moderate \\
\hline 4 & High & Major & $\begin{array}{l}\text { Extensive injuries, loss of production capability, off-site } \\
\text { release with no detrimental effects, major financial loss }\end{array}$ & Major \\
\hline 5 & Vey High & Catastrophic & $\begin{array}{l}\text { Death, toxic release off-site with detrimental effect, huge } \\
\text { financial loss }\end{array}$ & Catastrophic \\
\hline
\end{tabular}

Table 8. Hybrid of PMBOK and AS / NSZ 4360 used to construct a qualitative description of the impact of the safety risks using scale Categories of 1 $-5$

\begin{tabular}{|c|c|c|}
\hline Category Scale & Short description [3] & Detailed description [16] \\
\hline 1 & Very Low & No injuries, low financial loss \\
\hline 2 & Low & First aid treatment, on site release immediately contained, medium financial loss \\
\hline 3 & Moderate & $\begin{array}{l}\text { First aid treatment required, on site release contained with outside assistance, high } \\
\text { financial loss }\end{array}$ \\
\hline 4 & High & $\begin{array}{l}\text { Extensive injuries, loss of production capability, off-site release with no detrimental } \\
\text { effects, major financial loss }\end{array}$ \\
\hline 5 & Very High & Death, toxic release off-site with detrimental effect, huge financial loss \\
\hline
\end{tabular}


Table 9. Formulation of the impact scale (I) using a semi-quantitative method for the safety aspects

\begin{tabular}{|c|c|c|c|}
\hline Category Scale & & Description & Numerical value scale \\
\hline 1 & Very Low & No injuries, low financial loss & 0.05 \\
\hline 2 & Low & $\begin{array}{c}\text { First aid treatment, on site release immediately contained, } \\
\text { medium financial loss }\end{array}$ & 0.1 \\
\hline 3 & Moderate & $\begin{array}{c}\text { First aid treatment required, on site release contained with } \\
\text { outside assistance, high financial loss }\end{array}$ & 0.2 \\
\hline 4 & High & $\begin{array}{c}\text { Extensive injuries, loss of production capability, off-site } \\
\text { release with no detrimental effects, major financial loss }\end{array}$ & 0.4 \\
\hline 5 & Very High & $\begin{array}{c}\text { Death, toxic release off-site with detrimental effect, huge } \\
\text { financial loss }\end{array}$ & 0.8 \\
\hline
\end{tabular}

Table 10. Risk impacts on cost, quality, time and safety using a semi-quantitative scale.

\begin{tabular}{|c|c|c|c|c|c|c|}
\hline \multirow{2}{*}{$\begin{array}{l}\text { Category } \\
\text { Scale }\end{array}$} & \multirow{2}{*}{ Impact } & \multicolumn{4}{|c|}{ Description of Impact } & \multirow{2}{*}{$\begin{array}{l}\text { Numerica } \\
\text { value } \\
\text { scale }\end{array}$} \\
\hline & & Cost [13] & Time $[3,13]$ & Quality $[3,13]$ & Safety & \\
\hline 1 & Very Low & $\begin{array}{l}\text { Insignificant } \\
\text { cost }\end{array}$ & $\begin{array}{c}\text { Insignificant } \\
\text { time } \\
\text { increase }\end{array}$ & $\begin{array}{l}\text { Quality degradation } \\
\text { barely noticeable }\end{array}$ & No injuries, low financial loss & 0.05 \\
\hline 2 & Low & $\begin{array}{l}<10 \% \text { cost } \\
\text { increase }\end{array}$ & $\begin{array}{l}<5 \% \text { time } \\
\text { increase }\end{array}$ & $\begin{array}{l}\text { Only very demanding } \\
\text { applications are } \\
\text { affected }\end{array}$ & $\begin{array}{l}\text { First aid treatment, on site release } \\
\text { immediately contained, medium } \\
\text { financial loss }\end{array}$ & 0.1 \\
\hline 3 & Moderate & $\begin{array}{c}10-20 \% \text { cost } \\
\text { increase }\end{array}$ & $\begin{array}{l}5-10 \% \text { time } \\
\text { increase }\end{array}$ & $\begin{array}{l}\text { Quality reduction } \\
\text { requires sponsor } \\
\text { approval }\end{array}$ & $\begin{array}{c}\text { First aid treatment required, on } \\
\text { site release contained with } \\
\text { outside assistance, high financial } \\
\text { loss }\end{array}$ & 0.2 \\
\hline 4 & High & $\begin{array}{l}20-40 \% \text { cost } \\
\text { increase }\end{array}$ & $\begin{array}{l}10-20 \% \\
\text { time } \\
\text { increase }\end{array}$ & $\begin{array}{l}\text { Quality reduction } \\
\text { unacceptable to } \\
\text { sponsor }\end{array}$ & $\begin{array}{l}\text { Extensive injuries, loss of } \\
\text { production capability, off-site } \\
\text { release with no detrimental } \\
\text { effects, major financial loss }\end{array}$ & 0.4 \\
\hline 5 & $\begin{array}{l}\text { Very } \\
\text { High }\end{array}$ & $\begin{array}{l}>40 \% \text { cost } \\
\text { increase }\end{array}$ & $\begin{array}{l}>20 \% \text { time } \\
\text { increase }\end{array}$ & $\begin{array}{l}\text { Project end item } \\
\text { is effectively useless }\end{array}$ & $\begin{array}{l}\text { Death, toxic release off-site with } \\
\text { detrimental effect, huge financial } \\
\text { loss }\end{array}$ & 0.8 \\
\hline
\end{tabular}

The safety impact parameter model using the semi-quantitative method obtained from the research results as shown in Table 9 can be used in integrated project risk analysis in relation to cost, quality, time and safety. This is because it is aligned with the risk impact scale model using the semi-quantitative method for the variables of cost, quality and time [3, 13]. The semi-quantitative risk impact scale model with the variables of cost, quality and time from the related references and the safety variable obtained from the research results can be seen in Table 10.

\section{Conclusions}

The semi-quantitative scale model on the impact of safety risks was obtained from a hybrid formulation between the Project Management Body of Knowledge (PMBOK) guidelines by the Project Management Institute and the Standard Australian / Standard New Zealand (AS / NZS) 4300 by Standard Australian / New Zealand. The qualitative scale model obtained uses an ordinal scale of 1 to 5 with a description of the impact ranging from 1 to 5 in order, namely very low, low, moderate, high and very high. The numerical scale uses the cardinal scale of the nonlinear model in order of $0.05,0.1,0.2,0.4$ and 0.8 , adopted from the PMBOK guidelines. The operational descriptions were adopted from the 4300 (AS / NZS) guidelines. The safety risk impact scale model obtained can be used to analyze the integrated risk of the diamond constraint model, inclusive of the integration of risks in terms of cost, quality, time and safety.

\section{Acknowledgements}

Thanks go to P. D. Warsika, a colleague of the brainstorming team, for assisting us in this research. Thanks also go to Udayana University, Bali, Indonesia, for assisting in terms of the funding of this research.

\section{REFERENCES}

[1] E. N. Allouche, A. Gilcrist. Quantifying Construction Realated Social Costs, North American Society for Trenchless Technology (NASTT), New Orleans, Lusiana, 2004

[2] D. W. Borchartdt, G. Pesti, D. Sun, L. Ding. Capacity and Road User Cost Analysis of Selected Freeway Work Zones in Texas, Report 0-5619-1, Texas Trasportation Institute, 2009 
[3] PMI (Project Management Institute). A Guide to The Project Management Body of Knowledge (PMBOK), 3rd edition, USA, 2004.

[4] L. D. Radu. 2009. Qualitative, semi-quantitative and, quantitative methods for risk: Case of the Financial Audit, Online available from https://www.researchgate.net/publica tion $/ 46532735$

[5] A. Purnus, C.N. Bodea. Correlation between time and cost in quantitative risk of construction project, Procedia, Enselvier, 2014 .

[6] A. Rezaian. Time-Cost-Quality-Risk of Construction and Development Projects or Investment. Middle-East Journal of Scientific Research, Vol.10, No.2, 218-223, 2011

[7] A. Lester. Safety, The Fourth Project Management Criterion, Wellingtone, 2016, Online available from https://wellington e.co.uk/safety-project-management-triangle/

[8] A. Ferdinand. Management Research Methods. CV Indoprint, Semarang, Indonesia, 2011

[9] DPU (Depatemen Pekerjaan Umum/Ministry of Public Works). Construction and Building Guidelines Pd. T-02-2005-B About the Calculation of the Cost of Traffic Accidents Using The Gross Output (Human Capital) Method, Indonesia, 2005.

[10] PMPU (Peraturan Menteri Pekerjaan Umum/ Regulation of the Minister of Public Works). Regulation of the Minister of Public Works Number: 05 / PRT / M / 2014 concerning Guidelines for Occupational Safety and Health Management Systems (OSHMS) Construction in the Public Works Sector, Indonesia, 2014.

[11] S.S. Alizadeh, S.B. Mortazavi, M.M. Sepehri. Assessment of accident severity in the construction industry using the Bayesian theorem. International Journal of Occupational Safety and Ergonomics, Vol.21, No.ue 4, 551-557. 2015

[12] D. P. Purohit, D. A. Siddiqui, A.Nandan, D. P. Yadav. Hazard Identification and Risk Assessment in Construction Industry. International Journal of Applied Engineering Research, Vol.13, No.10, 7639-7667, 2018.

[13] S. T. Demir, D. J. Bryde, D. J. Fearon, E. G. Ochieng, A tool for integrating time, cost and quality perspectives in Probability Impact (P-I) Tables, International Journal of Project Organisation and Management, Vol.6, No.4, 303318, 2015. https://doi.org/10.1504/IJPOM.2014.066410

[14] D. C. Simmons, R. Dauwe, R. Gowland, Z. Gyenes, A. G. King, D. Riedstra, \& S. Schneiderbauer. Qualitative and quantitative approaches to risk assessment. Understanding Disaster Risk: Risk Assessment Methodologies and Examples, Chapter-2, 44-130, (2017).
[15] B. Barghi, S.S. Shadrokh, Qualitative and quantitative project risk assessment using a hybrid PMBOK model developed under uncertainty conditions. Heliyon, Vol.6, 1-22, 2019. https://doi.org/10.1016/j.heliyon.2019.e03097

[16] AS/NZS (Standards Australian/Standards New Zealand) Risk Management Guidelines Companion to AS/NZS 4360:2004, Handbook, Autralian, 2005.

[17] BSN (Badan Standarisasi Nasional/ National Standardization Agency). Grand Design of Risk Management Implementation in the National Standardization Agency 2018-2023, Indonesia, 2018.

[18] Anonim. Semi-Quantitative Risk Analysis Key Concepts, 2015, Online available from https://www.semanticscholar.o $\mathrm{rg} /$ paper/Semi-Quantitative-Risk-Analysis-Key-Concepts/b d2faad52454449633bf824568d512bd268342a3?p2df

[19] J.M. Andri'c, J. Wang, R. Zhong. Identifying the Critical Risks in Railway Projects Based on Fuzzy and Sensitivity Analysis: A Case Study of Belt and Road Projects, J. Sustainability, Vol.11, No.5, 1-18, 2019. https://doi.org/10. 3390/su11051302

[20] P.S. Godfrey and W. Halcrow. Control Risk: A Guide to the Systematic Management of Risk from Construction. E-Book, CIRIA, London, 1996.

[21] D. Vose. Risk Analysis: A quantitative guide. John Wiley \& Sons, Ltd, New York, 2008

[22] Anonim. Semi-Quantitative Risk Characterization, Chapter-4. 2009, Online available from http://www.fao.org/ 3/i1134e/i1134e04.pdf

[23] WHO (World Health Organization). Risk characterization of icrobiological hazards in food. Department of Food Safety and Zoonoses, Switzerland, 2009.

[24] M.B. Anthony. Occupational Health and Safety Risk Analysis Using AS / NZS 4360: 2004 Standard In Pulp \& Paper Companies, Scientific Journal of Industrial Engineering and Management, Kadiri University, Vol.2, No.2, $84-94,2019$.

[25] S. Bilir, G. E. Gurcanli. The New Severity Scale of Occupational Accidents for Construction Projects, 5th International Project and Construction Management Conference (IPCMC2018), Cyprus International University, Faculty of Engineering, Civil Engineering Department, North Cyprus, 2018.

[26] F. Božek. Semi-quantitative Risk Assessment, the Risk Position of the Entity. Presentation moodle- University of Defence Brno, Czech Republic, 2019 